\title{
Effects of Cytokine Blocking Agents on Hospital Mortality in Patients Admitted to ICU With Acute Respiratory Distress Syndrome by SARS-CoV2 Infection: An Observational Cohort Study
}

Irene Coloretti

Università degli studi di Modena e Reggio Emilia

\section{Stefano Busani}

Università degli studi di Modena e Reggio Emilia

Emanuela Biagioni

Università degli studi di Modena e Reggio Emilia

Sophie Venturelli

Università degli studi di Modena e Reggio Emilia

Elena Munari

Università degli studi di Modena e Reggio Emilia

Marco Sita

Università degli studi di Modena e Reggio Emilia

\section{Lorenzo Dallara}

Università degli studi di Modena e Reggio Emilia

Martina Tosi

Università degli studi di Modena e Reggio Emilia

\section{Enrico Clini}

Università degli studi di Modena e Reggio Emilia

Roberto Tonelli

Università degli studi di Modena e Reggio Emilia

\section{Riccardo Fantini}

Università degli studi di Modena e Reggio Emilia

Cristina Mussini

Università degli studi di Modena e Reggio Emilia

Marianna Meschiari

Università degli studi di Modena e Reggio Emilia

Giovanni Guaraldi

Università degli studi di Modena e Reggio Emilia

\section{Andrea Cossarizza}

Università degli studi di Modena e Reggio Emilia

\section{Gaetano Alfano}

Università degli studi di Modena e Reggio Emilia 
Massimo Girardis ( $\boldsymbol{\sim}$ girardis.massimo@unimo.it)

Università degli studi di Modena e Reggio Emilia

\section{Research Article}

Keywords: COVID19, Acute Respiratory Distress Syndrome, Tocilizumab, Anakinra, Intensive Care Unit, Mechanical Ventilation

Posted Date: August 13th, 2020

DOI: https://doi.org/10.21203/rs.3.rs-37561/v2

License: (a) (i) This work is licensed under a Creative Commons Attribution 4.0 International License. Read Full License 


\section{Abstract}

\section{Background}

The use of cytokine-blocking agents has been proposed to modulate the inflammatory response in patients with COVID19. Tocilizumab and Anakinra were included in the local protocol as an optional treatment in critically ill patients with acute respiratory distress syndrome (ARDS) by SARS-CoV2 infection. This cohort study evaluated the effects of therapy with cytokine blocking agents on in-hospital mortality in COVID19 patients requiring mechanical ventilation and admitted to intensive care unit.

\section{Methods}

The association between therapy with Tocilizumab or Anakinra and in-hospital mortality was assessed in consecutive adult COVID19 patients admitted to our ICU with moderate to severe ARDS. The association was evaluated by comparing patients who receive to those who did not receive Tocilizumab or Anakinra and by using different multivariable Cox models adjusted for variables related to poor outcome, for the propensity to be treated with Tocilizumab or Anakinra and after patient matching.

\section{Results}

Sixty-six patients who received immunotherapy (49 Tocilizumab, 17 Anakinra) and 28 patients who did not receive immunotherapy were included. The in-hospital crude mortality was $30,3 \%$ in treated patients and $50 \%$ in non-treated ( $\mathrm{OR} 0,77,95 \% \mathrm{Cl} 0,56-1,05, \mathrm{p}=0,069)$. The adjusted Cox model showed an association between therapy with immunotherapy and in-hospital mortality ( $\mathrm{HR} \mathrm{0,35,95 \%} \mathrm{Cl} 0,16-0,77, \mathrm{p}=0,009)$. This protective effect was further confirmed in the analysis adjusted for propensity score, in the propensity-matched cohort and in the cohort of patients with invasive mechanical ventilation within 2 hours after ICU admission.

\section{Conclusions}

Although important limitations, our study showed that cytokine-blocking agents seem to be safe and to improve survival in COVID-19 patients admitted to ICU with ARDS and the need of mechanical ventilation.

\section{Background}

Since February 20th, 2020 Italy has been overwhelmed by SARS-CoV-2 virus outbreak and several patients with interstitial pneumonia and respiratory failure requiring mechanical ventilation were admitted to our intensive care unit (ICU) [1]. Unfortunately, so far there are no validated therapies to prevent or treat the severe acute respiratory distress syndrome (ARDS) caused by this novel virus and, thus, the case-fatality rate in patients admitted to ICU is extremely high, ranging from 30 to $80 \%$ [2-7]. Therefore, along with the maintenance of vital functions by supportive treatments, effective therapies in COVID19 are urgently needed and several trials are underway worldwide for evaluating the effects of new and old antivirals agents, hydroxychloroquine, convalescent plasma, specific immunosuppressive agents and others [8-10].

In the last weeks, the scientific community provided a tremendous improvement in the knowledge of mechanisms involved in COVID-19 pathobiology. Uncontrolled immune response characterized by systemic hyper inflammation with an abnormal increase of circulating cytokines and chemokines (the so-called cytokine 
storm) is common in critically ill COVID-19 patients and seems to have a pivotal role in lung tissue damage, increase in vascular permeability and clots formation [11]. To reduce the burden of this hyperinflammatory state many authors postulated the use of drugs with selective (e.g. anti-interleukin 1 and 6) and unselective (e.g. steroids, immunoglobulins) block of inflammatory mediators. The assessment of serum levels of proinflammatory biomarkers and cytokines has become common in clinical practice for early recognizing COVID19 patients at risk for clinical worsening and who could benefit by the use of specific immunosuppressive agents [12].

On last February 25th, we admitted the first patient with severe COVID-19 pneumonia to our ICU. Fifteen days later, based on the above pathophysiological considerations and the early experiences reported [13], the use of Tocilizumab (a recombinant humanized monoclonal antibody directed against both the soluble interleukin- 6 receptor and the membrane-bound receptor) or Anakinra (a recombinant interleukin-1 receptor antagonist), in case of shortage of intravenous Tocilizumab, has been included in the local protocol for the management of COVID19 as an optional treatment in critically ill patients with the need of non-invasive or invasive ventilatory support because of moderate to severe ARDS.

This cohort study aimed to evaluate the effects of the therapy with Tocilizumab or Anakinra on in-hospital mortality in patients requiring mechanical ventilation for severe COVID-19 pneumonia and admitted to ICU. We hypothesized that the use of Tocilizumab or Anakinra would be safe and associated with in-hospital mortality rate reduction in the analysis adjusted for the major factors related to poor outcome.

\section{Methods}

\section{$\underline{\text { Design, }}$ Population and Protocol}

This retrospective cohort observational study included consecutive adult patients ( $\geq 18$ years) admitted to the ICU of University Hospital of Modena with ICU stay $>24$ hours, moderate to severe ARDS, requiring invasive or non-invasive mechanical ventilation and laboratory-confirmed SARS-CoV-2 infection from February 25th to April 6th. Moderate to severe ARDS was defined as new or worsening respiratory failure with bilateral opacities and $\mathrm{PaO} 2 / \mathrm{FiO} 2 \leq 200 \mathrm{mmHg}$ with positive end-expiratory pressure $\geq 5 \mathrm{cmH} 20$ not fully explained by cardiac failure, fluid overload, pleural effusions and lobar or lung collapse [14]. SARS-CoV-2 infection was defined as a positive result of real-time reverse transcriptase-polymerase chain reaction (RT-PCR) assay of nasopharyngeal swabs or lower respiratory tract specimens. The study was approved by the Ethics Committee of Area Vasta Nord Emilia Romagna (n. 289/2020, 7 April 2020) who deemed informed consent unnecessary because of the retrospective design.

All the patients received standard ICU monitoring and supportive care, including mechanical protective ventilation, as recommended by the WHO guidelines [15] and specific therapies according to national [16] and local protocol for COVID-19 treatment including hydroxychloroquine, azithromycin if suspicion of bacterial respiratory superinfection, low molecular weight heparin for prophylaxis of deep vein thrombosis according to individual bodyweight and renal function, and antiretroviral therapy with lopinavir/ritonavir or darunavir/cobicistat (removed on 22 March). The local protocol allowed the use of steroids (methylprednisolone $2 \mathrm{mg} / \mathrm{kg} /$ day) to prevent the onset of pulmonary fibrosis in patients who maintained a $\mathrm{PaO} 2 / \mathrm{FiO} 2$ ratio $<150$ for at least 7 days of mechanical ventilation [17]. 
Since March 5, for the reasons described above (see introduction), the local ICU management protocol included the option for off label use of Tocilizumab (TOCI) or Anakinra (ANA), when intravenous TOCI was not available due to market shortage, in patients with moderate or severe ARDS and the need of mechanical ventilation (noninvasive or invasive). Patients with coexistent infection other than COVID-19, chronic use of steroids or other immunosuppressive agent, neutrophils $<500 / \mathrm{mmc}$ or platelets $<50.000 / \mathrm{mmc}$, gastro-intestinal tract condition that might predispose to bowel perforation and severe hematologic, renal or liver impairment were excluded from this therapeutic option. Nevertheless, the decision for therapy with TOCI or ANA was left to the discretion of the treating team considering the benefit to risk ratio in the individual patient. TOCI was administered intravenously at the dosage of $8 \mathrm{mg} / \mathrm{kg}$ of body weight (up to a maximum dosage of $800 \mathrm{mg}$ per infusion) in two doses, 12 hours apart. ANA was used intravenously at the dose of $400 \mathrm{mg} / \mathrm{die}$ for 14 days or until the patient was weaned from mechanical ventilation or adverse events related to therapy occurred. The TOCI and ANA schedules were based on dosages indicated for the treatment of cytokine release syndrome [18] and macrophage activated syndrome $[19,20]$. The standard supportive management in ICU did not change during the study period, except for a more conservative approach in providing intubation and invasive ventilation in the first 2-3 weeks compared to the following weeks when non-invasive ventilation was used also in patients with severe ARDS and very low PaO2/FiO2 values.

Data collection and analysis

Demographics, co-morbidities, medications, and laboratory values were collected by reviewing electronic medical records. The primary endpoint was in-hospital survival after ICU admission. Secondary endpoints were ICU mortality, ICU-free days censored at day 30, invasive and non-invasive ventilator-free days (VFDs) at day 30 after ICU admission, the incidence of secondary infections within hospital stay. All enrolled patients achieved the follow-up period.

The association between immunotherapy and in-hospital mortality was estimated by multivariable Cox proportional hazards regression model including immunotherapy, variables with $p<0,2$ at unadjusted analysis (age, co-morbidities, SAPS II, PaO2/FiO2 ratio and invasive ventilation at ICU admission). To evaluate the independent association of TOCI and ANA with mortality, a second multivariable Cox proportional hazards regression model was built including the previous covariates with stratification of immunotherapies in the two different treatment arms.

To further reduce the effects of confounding variables we performed a secondary analysis by using propensity score as an additional covariate in Cox proportional hazards regression and for patients matching. The individual propensity to be treated with $\mathrm{TOCI}$ or ANA was estimated by a multivariable logistic regression model that included the same covariates as the Cox regression; the nearest-neighbour method was applied to the propensity-score matching analysis.

An additional sensitivity analysis included the same set of analyses was performed only in the population with invasive mechanical ventilation within 2 hours after ICU admission.

Non-Parametric and $\chi 2$ tests were used as appropriate for the unadjusted comparison between controls and treated patients of demographic and baseline values, and outcomes. Cumulative survival analysis censored at day 60 was performed using the Kaplan-Meier method and the log-rank test was then used to examine 
differences in the curves between the groups. Patients discharged from the hospital before day 60 were considered survived. All tests were two-tailed with $p$-value $<0.05$ considered significant. SPSS version 22.0 package (SPSS Inc., Chicago, IL, USA) was used to perform statistical analysis.

\section{Results}

In the study period, ninety-nine COVID19 patients were admitted to our ICU of whom 94 met the inclusion criteria. Sixty-six patients (70\%) received selective cytokine blockade therapy (immunotherapy group), 49 (52\%) with 2 doses of TOCl and 17 (18\%) with ANA for a median of 8 days (IQR 7-11). In 26 patients (53\%) the first dose of TOCI was administered before ICU admission (median time 24 -IQR 12-48 Hours) and in 23 (43\%) after ICU admission (median time 6 -IQR 0-24 Hours). ANA was started after ICU admission in all the patients (median time 4-IQR 0-24 Hours) and was stopped in 9 (53\%) patients for weaning from mechanical ventilation, in 4 (24\%) for death during treatment and $3(23 \%)$ patients completed the full therapy course.

Demographic and clinical characteristics at ICU admission were similar in patients who received and who did not receive selective cytokine blockade therapy with exception of percentage of patients undergoing invasive ventilation within 2 hours from admission $(p<0,005)$ and PaO2/FiO2 $(p=0,029)$ that were larger in control patients, and interleukin 6 blood concentration that was higher $(p=0,019)$ in immunotherapy group (Table 1$)$. Twenty-four out of the 44 patients in non-invasive ventilation within 2 hours after ICU admission were subsequently intubated during ICU stay (3 out 7 in the control group (43\%) and 21 out of $37(57 \%)$ in immunotherapy group, $p=0,48$ ). Fifty-six patients (14 in the control group and 43 in the immunotherapy group $(p=0,17))$ received steroids during ICU stay for a median of 5 days (IQR $5-7)$.

Crude analysis showed that selective cytokine blockade therapy provided $20 \%$ absolute risk reduction of inhospital mortality compared to controls (OR 0,77, 95\% Cl 0,56-1,05, p=0,069) (Table 2). The Kaplan Meyer analysis for cumulative in-hospital survival (Figure 1) shows a significative effect of immunotherapy as a protective strategy $(p=0,036)$. Cox regression multivariable analysis indicated that age, SAPS II and immunotherapy were related to mortality risk, with an improvement in survival by the use of TOCl or ANA (HR $0,35,95 \% \mathrm{Cl} 0,16-0,77, \mathrm{p}=0,009$ ) (Table 3 ). The main cause of death in both groups was a multiorgan failure due to persistent and intractable hypoxemia ( $n=15,75 \%$ in the Immunotherapy group and $n=11,79 \%$ in the controls)

Baseline and mortality rate at day 30 were similar in patients treated with ANA treated with TOCI (Table E1-E2). The Cox regression model with TOCI and ANA as separate covariates indicated that TOCl decreased (HR 0,31 $95 \% \mathrm{Cl} 0,13-0,73, p=0,007)$ and ANA showed a trend in decreasing the risk of mortality (HR 0,46-95\% $\mathrm{Cl} 0,17-$ $1,26, p=0,130)$.

The secondary multivariable analyses using the individual propensity for receiving therapy with TOCI and ANA as covariate confirmed the protective role of immunotherapy (HR 0,37- 95\% $\mathrm{Cl} 0,17-0,80, \mathrm{p}=0,012)$. The multivariable analysis including 11 controls and 55 immunotherapy patients matched by propensity-score (wellbalanced for all covariates) also indicated that the use of interleukin selective blockade agents is associated with reduced risk of mortality (HR 0,23-95\% $\mathrm{Cl} \mathrm{0,09-0,56,p=0,001)}$

The invasive ventilation free days $(p=0,035)$, total ventilation (invasive and non-invasive) free days $(P=0,132)$ as well as ICU free days $(p=0,07)$ at day-30 were larger in immunotherapy group. The rate of patients with new 
infections was similar in the 2 groups; the infections were sustained mostly by Gram-positive bacteria $(65,8 \%)$ with respiratory tract $(76,3 \%)$ and bloodstream $(28,9 \%)$ as main sites of infection. As for viral infections, 4 patients in the control group and 5 in the immunotherapy group were treated by Ganciclovir for cytomegalovirus reactivation; 1 patient who received ANA and 4 patients who received TOCI were treated with Acyclovir for herpes simplex virus type 1 reactivation. No differences in secondary outcomes were observed between patients treated with ANA o TOCI (Table E2).

The sensitivity analysis in patients with invasive ventilation at ICU admission (21 patients in TOCI, 8 in ANA and 21 in controls) confirmed the potential association between selective cytokine blockade therapy and the reduced risk of in-hospital mortality (Table E3- E5)

\section{Discussion}

The results of this cohort observational study indicate that selective cytokine blockade with Tocilizumab or Anakinra in critically ill patients with moderate to severe ARDS pneumonia and need of mechanical ventilation seems to be well tolerated and to improve in-hospital survival rate.

Based on recent reports [3, 21], the pathobiology of interstitial pneumonia and acute respiratory failure by SARSCoV-2 infection relies on the predominant role of hyper-inflammation in the context of a complex dysregulated immune function [22]. As observed by others [3, 23], our patients showed a pronounced pro-inflammatory state at ICU admission with elevated serum CRP, D-Dimer, LDH and IL6 levels associated with lymphopenia. In this Due to the poor outcome observed in the first reports on COVID19 patients requiring ICU admission, the attractive hypothesis of controlling the exaggerated cytokine response by using different immunomodulating agents has been early proposed [24] and many randomized trials are ongoing.

TOCI and ANA, among immunomodulatory drugs, represent two treatment options in this context. TOCl, a selective interleukin- 6 receptor antagonist, was approved for the treatment of autoimmune diseases and Chimeric Antigen Receptor T-Cell Therapy-Induced Cytokine Release Syndrome [25]. Early reporting of clinical experiences with TOCI in COVID-19 patients have been recently published. In a single centre study from Wuhan including 15 patients TOCl appeared to be an effective treatment option in patients with cytokine storm [13]. In a retrospective analysis of 25 unmatched ICU patients, $\mathrm{TOCl}$ at the median dose of $5,7 \mathrm{mg} / \mathrm{Kg}$ showed a significant reduction in invasive mechanical ventilation at day 14 , although $90 \%$ of patients showed adverse events [26]. A prospective multi-centre safety study on 66 patients reported no moderate to severe adverse events related to $\mathrm{TOCI}$ with a significant improvement in $\mathrm{PaO} 2 / \mathrm{FiO} 2$ ratio, ferritin, C-reactive protein, D-dimer and lymphocytes count at day 14 [27]. In a single-centre study including 100 unmatched COVID-19 patients with mechanical ventilation, the authors observed an improvement of the respiratory severity using a diseasespecific scale and the decreasing of laboratory inflammation parameters after two intravenous administrations of $8 \mathrm{mg} / \mathrm{kg}$ of TOCl. A French retrospective case- control study reported a $50 \%$ difference in primary composite end-point (death and/or ICU admission) in 20 patients treated with TOCI (unreported dosage) compared to 25 controls [28].

As refers to ANA, it is a recombinant IL-1 receptor antagonist administered to treat autoinflammatory disorders and recently used in post-myocardial infarction remodelling and diabetes [29]. In the context of COVID-19 acute respiratory distress syndrome, a retrospective study was conducted on 29 patients treated with high-dosage 
ANA compared to 16 controls; patients were non-invasively ventilated outside of the ICU. Compared with standard treatment, high-dose ANA was associated with a higher survival rate at 21 days and with a reduction in C-reactive protein and with progressive improvement in $\mathrm{PaO} 2 / \mathrm{FiO} 2$. However, high-dose treatment was discontinued for adverse events in $24 \%$ of the treated patients [30].

To our knowledge, our study is the first to have evaluated the effects of the selective cytokine blockade on inhospital mortality in ICU admitted patients requiring mechanical ventilation for ARDS due to COVID19. Beyond the significant risk reduction compared to our controls, the in-hospital mortality $(36,2 \%$ in all the patients and $54 \%$ in those with invasive ventilation at ICU admission) observed in our patients treated with selective cytokine blockade was also lower than mortality observed in other reports, even when only patients underwent invasive ventilation are considered. A large case series of ICU patients coming from Wuhan, China, showed an overall mortality rate at day 28 of $39 \%$ but increased to $97 \%$ in patients with invasive mechanical ventilation. Interestingly, this high mortality rate in intubated patients has been attributed to possible late use of invasive ventilation [31]. Another retrospective study coming from Wuhan enrolled 52 critically ill ICU patients with a 28day mortality rate of $61,5 \%$ [6]. An Italian case series of 73 intubated patients had a median follow-up time of 19 days with a mortality rate of $23,3 \%$ and with almost half of the patients studied still invasively ventilated at that time-point [32]. In the Italian Lombardy ICU

Network series, the overall mortality rate of patients admitted in ICU was 48,3\% (1926 died and 2062 alive) with $91(4,4 \%)$ patients still in ICU on the date of publication [33]. Among 5700 hospitalized patients in the New York Area, 373 patients needed ICU care with an ICU mortality rate of 78\% [34]. An early report from Washington State reported an ICU mortality rate of $67 \%$ in 21 critically ill patients [7]. Finally, the ICNARC report on COVID-19 updated on 1st May showed an ICU mortality of $62 \%$ in 3508 patients with advanced respiratory support [35].

Remarkably, following previous reports, we did not observe any severe adverse event attributable to the use of TOCI or ANA [27]. The rate of secondary infections, mostly ventilator acquired pneumonia and catheter-related bloodstream infections by Gram-positive microorganisms, was high compared to no-COVID19 patients admitted to our ICU (internal data from Prosafe- Giviti project https://giviti.marionegri.it) but the use of cytokine selective blockade therapy did not increase the risk in comparison with controls treated in our centre. Nevertheless, in our cohort, the incidence of adverse events by ANA and TOCI could have been underestimated because of frequent clinical and laboratory alterations occurring in critically ill patients with severe ARDS or other organ dysfunctions. In fact, in 5 patients treated with cytokine blocking agents and long ICU stay we observed late reactivation of herpes simplex virus type 1 and, besides, two COVID19 patients treated with TOCI in other hospitals were transferred to our ICU for acute liver failure, without ARDS, due to herpes simplex virus type 1 reactivation (submitted for publication elsewhere).

Our study had several limitations that are mainly due to the observational design and to the small size of the cohort studied. Although the use of propensity score for adjusting the multivariable analysis and for patients matching is considered an effective method in non-randomized trials, it is possible that some amount of unmeasured confounding factors still remains. Nevertheless, it is noteworthy the all the data analysis (unadjusted, adjusted without and with propensity score) pointed out the same signal with a potential benefit in terms of survival by using selective cytokine blockade. The change of intubation rules during the study period with more permissive use of non- invasive ventilation in patients with severe ARDS could have introduced a bias. However, the sensitivity analysis in patients with invasive ventilation at ICU admission (within 2 hours) 
confirmed the reduction in mortality by using TOCI and ANA (Table E3-E5). The small number of patients treated with ANA and the different timing of administration of the two drugs hinder more robust analysis on the potential different effect of TOCI and ANA on patient survival, even if Cox multivariable regression seem to indicate a greater effect when using TOCI.

\section{Conclusions}

In conclusion, our experience indicated that Tocilizumab and Anakinra appear to be safe and to improve survival in patients with moderate to severe ARDS by SARS-Cov-2 infection. In a context of unproven therapies, the use of drugs able to provide a selective cytokine blockade may represent a promising therapeutic option in the treatment of COVID19 patients mechanically ventilated in ICU. Immediate confirmatory studies are needed to address an unmet medical need in the therapeutic management of these patients with an extremely high mortality rate.

\section{Abbreviations}

ANA: Anakinra

ARDS: acute respiratory distress syndrome COVID-19: Coronavirus disease -19

CRP: C-reactive protein

FiO2: fraction of oxygen in inspired mixture ICU: Intensive Care Unit

IL6: Interleukin-6

LDH: Lactate dehydrogenase

PaO2: arterial partial pressure of oxygen PCT: procalcitonin

TOCI: Tocilizumab

SOFA: simplified organ failure assessment, SAPS II: Simplified Acute Physiological Score II

\section{Declarations}

\section{Ethics approval and consent to participate}

The study was approved by the Ethics Committee of Area Vasta Nord Emilia Romagna (n. 289/2020, 7 April 2020) who deemed informed consent unnecessary because of the retrospective design.

Consent for publication

Not applicable 
The datasets used and/or analysed during the current study are available from the corresponding author on reasonable request.

\section{Authors' contributions}

$\mathrm{Cl}, \mathrm{BS}, \mathrm{TM}, \mathrm{GM}$ : design of the study, analysis and interpretation of data and drafting the manuscript; $\mathrm{BE}, \mathrm{SV}, \mathrm{EM}$, SM, DL, FR, MM: collection and analysis of data; CE, TR, MC, GG, CA: revising the manuscript critically for important intellectual content.

\section{Acknowledgements}

We are more than grateful to nurses and associated healthcare personnel of the Modena University Hospital for the unbelievable and restless activity during the COVID19 emergency. A special word of thanks to the Medical Direction, Clinical Engineering, and Information Technology Departments of the Hospital for the tremendous effort in organization and support of clinical activities.

\section{References}

1. Grasselli G, Zangrillo A, Zanella A, et al (2020) Baseline Characteristics and Outcomes of 1591 Patients Infected With SARS-CoV-2 Admitted to ICUs of the Lombardy Region, Italy. JAMA. https://doi.org/10.1001/jama.2020.5394

2. Wu C, Chen X, Cai Y, et al (2020) Risk Factors Associated With Acute Respiratory Distress Syndrome and Death in Patients With Coronavirus Disease 2019 Pneumonia in Wuhan, JAMA Intern Med. https://doi.org/10.1001/jamainternmed.2020.0994

3. Zhou F, Yu T, Du R, et al (2020) Clinical course and risk factors for mortality of adult inpatients with COVID19 in Wuhan, China: a retrospective cohort study. Lancet 395:1054-1062. https://doi.org/10.1016/S01406736(20)30566-3

4. Bhatraju PK, Ghassemieh BJ, Nichols M, et al (2020) Covid-19 in Critically III Patients in the Seattle Region Case Series. N Engl J Med. https://doi.org/10.1056/NEJMoa2004500

5. Huang C, Wang Y, Li X, et al (2020) Clinical features of patients infected with 2019 novel coronavirus in Wuhan, China. Lancet 395:497-506. https://doi.org/10.1016/S0140-6736(20)30183-5

6. Yang X, Yu Y, Xu J, et al (2020) Clinical course and outcomes of critically ill patients with SARS- CoV-2 pneumonia in Wuhan, China: a single-centered, retrospective, observational study. Lancet Respir Med 8:475-481. https://doi.org/10.1016/S2213-2600(20)30079-5

7. Arentz M, Yim E, Klaff L, et al (2020) Characteristics and Outcomes of 21 Critically III Patients With COVID19 in Washington State. JAMA. https://doi.org/10.1001/jama.2020.4326

8. Pascarella G, Strumia A, Piliego C, et al (2020) COVID-19 diagnosis and management: a comprehensive review. J Intern Med. https://doi.org/10.1111/joim.13091 
9. Wang Y, Zhang D, Du G, et al (2020) Remdesivir in adults with severe COVID-19: a randomised, double-blind, placebo-controlled, multicentre trial. Lancet 395:1569-1578. https://doi.org/10.1016/S0140-

$6736(20) 31022-9$

10. RECOVERY Collaborative Group, Horby P, Lim WS, et al (2020) Dexamethasone in Hospitalized Patients with Covid-19 - Preliminary Report. N Engl J Med. https://doi.org/10.1056/NEJMoa2021436

11. Jose RJ, Manuel A (2020) COVID-19 cytokine storm: the interplay between inflammation and coagulation. Lancet Respir Med. https://doi.org/10.1016/S2213-2600(20)30216-2

12. Ye Q, Wang B, Mao J (2020) The pathogenesis and treatment of the 'Cytokine Storm' in COVID-19. J Infect. https://doi.org/10.1016/j.jinf.2020.03.037

13. Luo P, Liu Y, Qiu L, et al (2020) Tocilizumab treatment in COVID-19: A single center experience. J Med Virol. https://doi.org/10.1002/jmv.25801

14. ARDS Definition Task Force, Ranieri VM, Rubenfeld GD, et al (2012) Acute respiratory distress syndrome: the Berlin Definition. JAMA 307:2526-2533. https://doi.org/10.1001/jama.2012.5669

15. World Health Organization. Clinical management of severe acute respiratory infection (SARI) when COVID19 disease is suspected: interim guidance, 13 March 2020 (license: CC BY- NC- SA 3.0 IGO

16. National Society of Infectious Diseases' (SIMIT) Guidelines for the managment of COVID-19 infection. Available at: http://www.simit.org/medias/1569-covid19-vademecum-13-03-pdf Last access April 5th 2020.

17. Steinberg KP, Hudson LD, Goodman RB, et al (2006) Efficacy and safety of corticosteroids for persistent acute respiratory distress syndrome. N Engl J Med 354:1671-1684.

https://doi.org/10.1056/NEJMoa051693

18. Le RQ, Li L, Yuan W, et al (2018) FDA Approval Summary: Tocilizumab for Treatment of Chimeric Antigen Receptor T Cell-Induced Severe or Life-Threatening Cytokine Release Syndrome. Oncologist 23:943-947. https://doi.org/10.1634/theoncologist.2018-0028

19. Mehta P, Cron RQ, Hartwell J, et al (2020) Silencing the cytokine storm: the use of intravenous anakinra in haemophagocytic lymphohistiocytosis or macrophage activation syndrome. Lancet Rheumatol. https://doi.org/10.1016/S2665-9913(20)30096-5

20. Futami M, Suzuki K, Kato S, et al (2020) The novel multi-cytokine inhibitor TO-207 specifically inhibits proinflammatory cytokine secretion in monocytes without affecting the killing ability of CAR T cells. PLoS ONE 15:e0231896. https://doi.org/10.1371/journal.pone.0231896

21. Ruan Q, Yang K, Wang W, et al (2020) Clinical predictors of mortality due to COVID-19 based on an analysis of data of 150 patients from Wuhan, China. Intensive Care Med 46:846-848.

https://doi.org/10.1007/s00134-020-05991-x

Page $11 / 16$ 
22. Giamarellos-Bourboulis EJ, Netea MG, Rovina N, et al (2020) Complex Immune Dysregulation in COVID-19 Patients with Severe Respiratory Failure. Cell Host Microbe. https://doi.org/10.1016/j.chom.2020.04.009

23. Lippi G, Plebani M (2020) Laboratory abnormalities in patients with COVID-2019 infection. Clin Chem Lab Med. https://doi.org/10.1515/cclm-2020-0198

24. Mehta P, McAuley DF, Brown M, et al (2020) COVID-19: consider cytokine storm syndromes and immunosuppression. Lancet 395:1033-1034. https://doi.org/10.1016/S0140- 6736(20)30628-0

25. Rubbert-Roth A, Furst DE, Nebesky JM, et al (2018) A Review of Recent Advances Using Tocilizumab in the Treatment of Rheumatic Diseases. Rheumatol Ther 5:21-42. https://doi.org/10.1007/s40744-018-0102-x

26. Alattar R, Ibrahim TBH, Shaar SH, et al (2020) Tocilizumab for the treatment of severe coronavirus disease 2019. J Med Virol. https://doi.org/10.1002/jmv.25964

27. Sciascia S, Aprà F, Baffa A, et al (2020) Pilot prospective open, single-arm multicentre study on off-label use of tocilizumab in patients with severe COVID-19. Clin Exp Rheumatol

28. Klopfenstein T, Zayet S, Lohse A, et al (2020) Tocilizumab therapy reduced intensive care unit admissions and/or mortality in COVID-19 patients. Med Mal Infect. https://doi.org/10.1016/j.medmal.2020.05.001

29. Dinarello CA, van der Meer JWM (2013) Treating inflammation by blocking interleukin-1 in humans. Semin Immunol 25:469-484. https://doi.org/10.1016/j.smim.2013.10.008

30. Cavalli G, De Luca G, Campochiaro C, et al (2020) Interleukin-1 blockade with high-dose anakinra in patients with COVID-19, acute respiratory distress syndrome, and hyperinflammation: a retrospective cohort study. The Lancet Rheumatology S2665991320301272. https://doi.org/10.1016/S2665-9913(20)30127-2

31. Wang Y, Lu X, Chen H, et al (2020) Clinical Course and Outcomes of 344 Intensive Care Patients with COVID-19. Am J Respir Crit Care Med. https://doi.org/10.1164/rccm.202003- 0736LE

32. Zangrillo A, Beretta L, Scandroglio AM, et al (2020) Characteristics, treatment, outcomes and cause of death of invasively ventilated patients with COVID-19 ARDS in Milan, Italy. Crit Care Resusc

33. Grasselli G, Greco M, Zanella A, et al (2020) Risk Factors Associated With Mortality Among Patients With COVID-19 in Intensive Care Units in Lombardy, Italy. JAMA Intern Med.

https://doi.org/10.1001/jamainternmed.2020.3539

34. Richardson S, Hirsch JS, Narasimhan M, et al (2020) Presenting Characteristics, Comorbidities, and Outcomes Among 5700 Patients Hospitalized With COVID-19 in the New York City Area. JAMA. https://doi.org/10.1001/jama.2020.6775

35. ICNARC COVID-19 report, May 1st 2020, https://icnarc.org/Our- Audit/Audits/Cmp/Reports

\section{Tables}

Table 1. Demographic and characteristics of the study populations 


\begin{tabular}{|c|c|c|c|c|}
\hline & $\begin{array}{l}\text { ALL } \\
\quad \text { PATIENTS } \\
(n=94)\end{array}$ & $\begin{array}{l}\text { CONTROL } \\
(\mathrm{n}=28)\end{array}$ & $\begin{array}{l}\text { IMMUNOTHERAPY } \\
(\mathrm{n}=66)\end{array}$ & $\begin{array}{c}P \\
\text { value }\end{array}$ \\
\hline Age (median, IQR) & $63(56-70)$ & $62(55-68)$ & $63(57-71)$ & 0,297 \\
\hline Sex, male (n, \%) & $75(79,8)$ & $22(78,6)$ & $53(80,3)$ & 0,848 \\
\hline Comorbidities (n,\%) & $67(71,3)$ & $22(78,6)$ & $45(68,2)$ & 0,309 \\
\hline Hypertension & $47(50)$ & $14(50)$ & $33(50)$ & \\
\hline Body Mass Index > 30 & $14(14,9)$ & $4(14,3)$ & $10(15,2)$ & \\
\hline Hyperlipidaemia & $6(6,4)$ & $2(7,1)$ & $4(6,1)$ & \\
\hline Diabetes & $15(15,9)$ & $6(21,4)$ & $9(13,6)$ & \\
\hline Any Other & $27(28,7)$ & $6(21,4)$ & $21(31,8)$ & \\
\hline SOFA (median, IQR) & $4(3-5)$ & $4(3-6)$ & $4(3-5)$ & 0,849 \\
\hline SAPS II (median, IQR) & $31,5(27-37)$ & $30(25-38)$ & $32(27-37)$ & 0,646 \\
\hline $\begin{array}{l}\text { Ventilation at ICU } \\
\text { admission }(n, \%)\end{array}$ & & & & 0,006 \\
\hline Invasivea & $50(52,3)$ & $21(75)$ & $29(43,9)$ & \\
\hline Non-invasive & $44(46,8)$ & $7(25)$ & $37(56,1)$ & \\
\hline $\begin{array}{l}\mathrm{PaO2} / \mathrm{FiO2}(\mathrm{mmHg}, \\
\text { median, IQR) }\end{array}$ & $100(80-123)$ & $113(86-161)$ & 96 (74-117) & 0,029 \\
\hline $\begin{array}{l}\text { D-dimer (ng/ml; median, } \\
\text { IQR) }\end{array}$ & $\begin{array}{c}1985(870- \\
3700) \\
\end{array}$ & $\begin{array}{c}1915(750- \\
2660) \\
\end{array}$ & $2085(940-8650)$ & 0,110 \\
\hline LDH (U/L; median, IQR) & $762(611-1031)$ & $\begin{array}{c}700,5(588- \\
1039,5) \\
\end{array}$ & $774(655-1031)$ & 0,549 \\
\hline $\begin{array}{l}\text { CRP (mg/L; median, } \\
\text { IQR) }\end{array}$ & $15,4(6,2-22,7)$ & $16,3(7,5-26,2)$ & $15,3(6,1-21,1)$ & 0,359 \\
\hline $\begin{array}{l}\text { PCT (ng, ml; median, } \\
\text { IQR) }\end{array}$ & $0,3(0,1-1,1)$ & $0,4(0,2-0,8)$ & $0,3(0,1-1,2)$ & 0,351 \\
\hline $\begin{array}{l}\text { IL6 (pg/ml; median, } \\
\text { IQR) }{ }_{\mathrm{b}}\end{array}$ & $\begin{array}{c}452,2(207,2- \\
1483,3)\end{array}$ & $\begin{array}{l}242,9(115,5- \\
386)\end{array}$ & $541,6(214,5-1526)$ & 0,019 \\
\hline $\begin{array}{l}\text { Lymphocyte count } \\
\text { (cells/mcl; median, } \\
\text { IQR) }\end{array}$ & $\begin{array}{l}0,64(0,42- \\
0,89)\end{array}$ & $\begin{array}{l}0,56(0,39- \\
0,85)\end{array}$ & $0,66(0,46-0,91)$ & 0,215 \\
\hline
\end{tabular}

SOFA: simplified organ failure assessment, SAPS : Simplified Acute Physiological Score II, PaO2: arterial partial pressure of oxygen, FiO2: fraction of oxygen in inspired mixture, LDH: Lactate dehydrogenase; CRP: C-reactive protein; PCT: procalcitonin; IL6: interleukin 6

a within 2 hours after ICU admission

b Measured in 65 patients, 10 controls, 55 Immunotherapy; 
Table 2 - Main outcomes in all population, controls and treated patients

\begin{tabular}{|c|c|c|c|c|}
\hline & $\begin{array}{l}\text { ALL } \\
\qquad \begin{array}{l}\text { PATIENTS } \\
(\mathrm{n}=94)\end{array}\end{array}$ & $\begin{array}{l}\text { CONTROL } \\
(n=28)\end{array}$ & $\begin{array}{l}\text { IMMUNOTHERAPY } \\
(\mathrm{n}=66)\end{array}$ & $\begin{array}{c}\mathrm{P} \\
\text { value }\end{array}$ \\
\hline $\begin{array}{l}\text { Hospital } \\
\text { mortality (n, \%) }\end{array}$ & $34(36,2)$ & $14(50,0)$ & $20(30,3)$ & 0,069 \\
\hline $\begin{array}{l}\text { 30-day } \\
\text { mortality (n, } \\
\%)\end{array}$ & $29(30,9)$ & $12(42,9)$ & $17(25,8)$ & 0,101 \\
\hline $\begin{array}{l}\text { ICU } \\
\text { mortality (n, } \\
\%)\end{array}$ & $27(28,7)$ & $11(39,3)$ & $16(24,2)$ & 0,140 \\
\hline $\begin{array}{l}\text { ICU-free days at } \\
30 \text { day } \\
\text { (median, IQR) }\end{array}$ & $16,5(0-25)$ & $0(0-22)$ & $18,5(0-26)$ & 0,072 \\
\hline $\begin{array}{l}\text { Invasive } \\
\text { ventilation free } \\
\text { days at 30-day } \\
\text { (median, IQR) }\end{array}$ & $20,5(0-28)$ & $0(0-26)$ & $22,5(0-29)$ & 0,035 \\
\hline $\begin{array}{l}\text { Ventilation-free } \\
\text { days at 30- } \\
\text { day } \\
\text { (median,IQR) }\end{array}$ & $16,5(0-25)$ & $0(0-23,5)$ & $18,5(0-26)$ & 0,132 \\
\hline $\begin{array}{l}\text { Patients with new } \\
\text { bacterial } \\
\text { infections during } \\
\text { hospital stay } \\
(\mathrm{n}, \%)\end{array}$ & $38(40,4)$ & $11(39,3)$ & $27(40,9)$ & 0,883 \\
\hline
\end{tabular}

Table 3- Odds ratios and confidence interval obtained by unadjusted univariate and adjusted Cox regression analysis for in-hospital mortality. Data for survived and no survived during hospital stay are also reported 


\begin{tabular}{|c|c|c|c|c|}
\hline & $\begin{array}{l}\text { Survived } \\
(\mathrm{n}=60)\end{array}$ & $\begin{array}{l}\text { Not } \\
\text { Survived } \\
(n=34)\end{array}$ & $\begin{array}{l}\text { Unadjusted OR } \\
\qquad(95 \% \mathrm{CI}) \\
\text { p value }\end{array}$ & $\begin{array}{l}\text { Adjusted HR } \\
\text { (95\% CI); } \\
\text { p value }\end{array}$ \\
\hline $\begin{array}{l}\text { Age } \\
\text { (median; IQR) }\end{array}$ & $61(54-67)$ & $69(62-75)$ & $\begin{array}{c}0,90(0,85- \\
0,96) \\
<0,001\end{array}$ & $\begin{array}{c}1,05(1,00-1,11) \\
0,045\end{array}$ \\
\hline $\begin{array}{l}\text { Comorbidities } \\
(\mathrm{n}, \%)\end{array}$ & $38(63,3)$ & $29(85,3)$ & $\begin{array}{c}1,44(1,09- \\
1,89) \\
\mathbf{0 , 0 1 9}\end{array}$ & $\begin{array}{c}1,32(0,41-4,30) \\
\mathbf{0 , 6 4 0}\end{array}$ \\
\hline $\begin{array}{l}\text { SAPS II score } \\
\text { (median; IQR) }\end{array}$ & $\begin{array}{c}27(24,5- \\
32)\end{array}$ & $36(34-43)$ & $\begin{array}{c}0,883(0,83- \\
0,94) \\
<0,001\end{array}$ & $\begin{array}{c}1,05(1,01-1,09) \\
\mathbf{0 , 0 2 6}\end{array}$ \\
\hline $\begin{array}{l}\mathrm{PaO} 2 / \mathrm{FiO} 2 \text { at ICU } \\
\text { admission } \\
\text { (median, IQR) }\end{array}$ & $\begin{array}{c}104(84- \\
132)\end{array}$ & $\begin{array}{c}91(73- \\
116)\end{array}$ & $\begin{array}{c}1,01(1,00- \\
1,02) \\
0,172\end{array}$ & $\begin{array}{c}0,99(0,99-1,00) \\
\mathbf{0 , 1 7 5}\end{array}$ \\
\hline $\begin{array}{ll}\text { Invasive } & \text { at ICU } \\
\text { ventilation } & \\
\text { admission a } & \\
(\mathrm{n} ; \%) & \end{array}$ & $23(38,3)$ & $27(79,4)$ & $\begin{array}{c}1,83(1,32- \\
2,53) \\
<0,001\end{array}$ & $\begin{array}{c}2,34(0,96-5,74) \\
\mathbf{0 , 0 6 3}\end{array}$ \\
\hline $\begin{array}{l}\text { Immunotherapy } \\
(\mathrm{n} ; \%)\end{array}$ & $46(76,7)$ & $20(58,8)$ & $\begin{array}{c}0,72(0,48- \\
1,07) \\
0,058\end{array}$ & $\begin{array}{c}0,35(0,16-0,77) \\
\mathbf{0 , 0 0 9}\end{array}$ \\
\hline
\end{tabular}

SAPS II : Simplified Acute Physiological Score II a within 2 hours after ICU admission

\section{Figures}




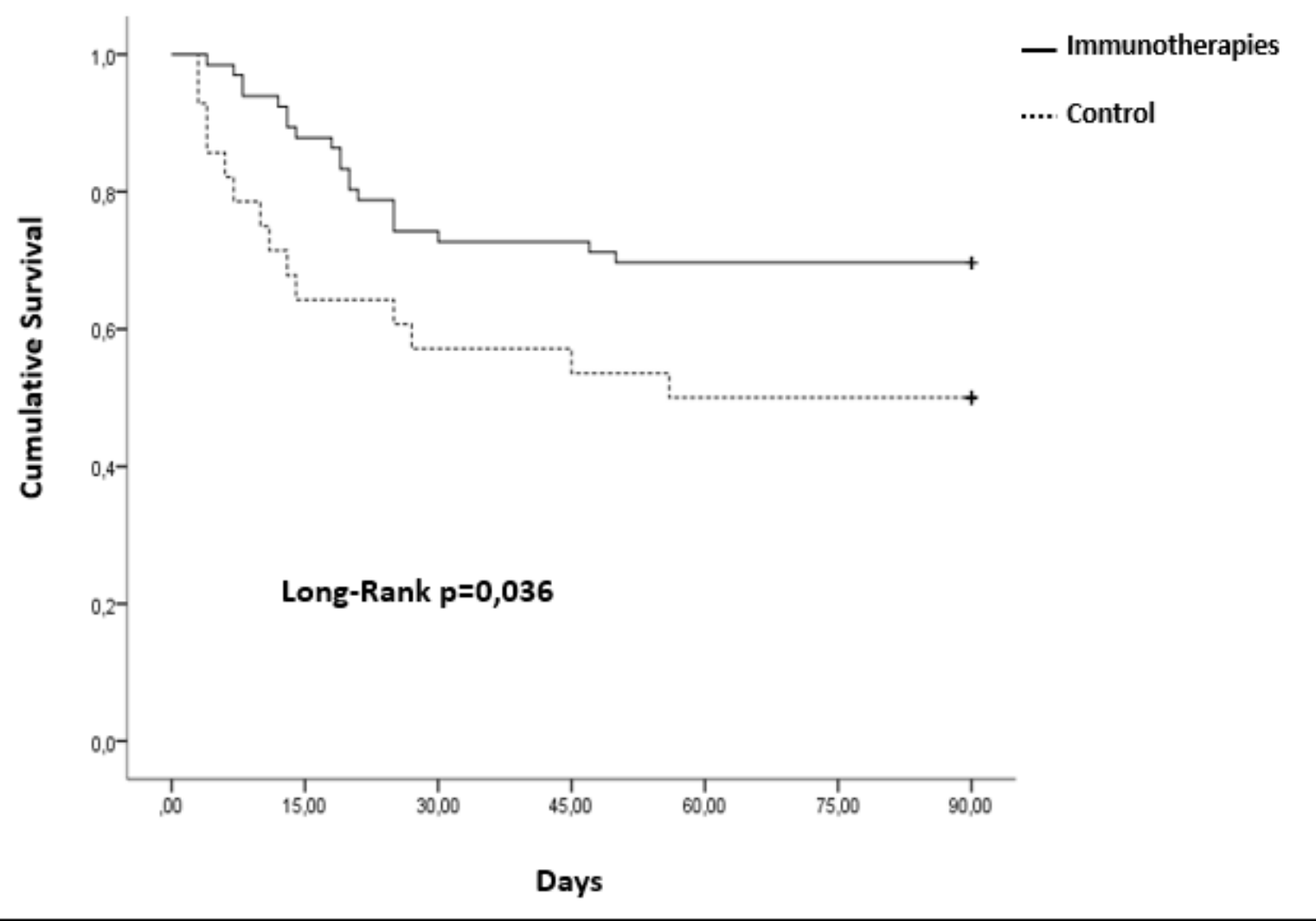

Figure 1

Kaplan Meyer Curves for survival probability at day 30

\section{Supplementary Files}

This is a list of supplementary files associated with this preprint. Click to download.

- Tables1final.jpg

- TableS2.png

- Tables3.png

- Tables4final.jpg

- TableS5.png 